\title{
About the Editor
}

Dr. Kolla Bhanu Prakash is working as professor and research group head in CSE Department, K L University, Vijayawada, Andhra Pradesh, India. He received his M.Sc and M.Phil in physics from Acharya Nagarjuna University, Guntur, India, and M.E. and Ph.D. in Computer Science Engineering from Sathyabama University, Chennai, India. Dr. Kolla Bhanu Prakash has more than 15 years of experience working in academia, research, teaching, and academic administration. His current research interests include Internet of things, deep learning, data science, smart grids, and image processing. Dr. K. Bhanu Prakash is IEEE Senior Member. He is Fellow-ISRD, Treasurer - ACM Amaravathi Chapter, India, LMISTE, MIAENG, and SMIRED. He has reviewed more than 100 peerreviewed journals and these are indexed in Publons. He is the editor for four books in Springer, Wiley, and De Gruyter publishers. He published 45 research papers, four patents, five books and four accepted. He is the recipient of Best Researcher Award. He is a frequent editorial board member and TPC member in flagship conferences and refereed journals. He is a reviewer for the IEEE Access journal. 
